\title{
Meteorite Chelyabinsk: Features of Destruction
}

\author{
Olga G. Gladysheva
}

Astrophysical Department of Ioffe Institute, St. Petersburg, Russia

Correspondence to: Olga G. Gladysheva, Olga.Gladysheva@mail.ioffe.ru

Keywords: Meteorites, Comets, Atmospheric Effects

Received: October 25, $2018 \quad$ Accepted: November 26, $2018 \quad$ Published: November 30, 2018

Copyright (C) 2018 by author and Scientific Research Publishing Inc.

This work is licensed under the Creative Commons Attribution International License (CC BY 4.0).

http://creativecommons.org/licenses/by/4.0/

\section{Open Access}

\section{ABSTRACT}

A space object exploded near the city of Chelyabinsk on February 15, 2013. Meteorite fragments reached the Earth's surface, and accordingly we may consider this space object to have been a meteorite. However, this event showed a number of features not corresponding to the destruction of a meteorite. The space object began to disintegrate at an altitude of 70 $\mathrm{km}$ when pressure (dynamical loads) on its front surface was $\sim 6.7 \times 10^{3} \mathrm{~N} \cdot \mathrm{m}^{-2}$. The substance from the object's surface was not blown off by drops, as at ablation, but was dumped by jets over a distance up to $1 \mathrm{~km}$. The trail of this space object visually reminded us of a jet aircraft's contrail, made up of water. But there is no enough water at altitudes of $30-70 \mathrm{~km}$. It may be assumed that the object itself delivered water to these altitudes. The calculation of gas rise over the trail showed that the temperature in some parts of this trail was about 900 K. Heating of large masses of gas can be explained not only by the release of kinetic energy of the space object, but also by combustion processes of its substance. Thus, it was concluded that the meteorite could have been delivered by a comet.

\section{INTRODUCTION}

A space object give then name "Chelyabinsk meteorite" exploded in the Earth's atmosphere on February 15,2013 . This object flew along a sloping trajectory with an angle of inclination to the Earth's surface equal to $\sim 17^{\circ}$. The speed at which the object entered the Earth's atmosphere was defined as $19 \mathrm{~km} / \mathrm{s}$. The energy $\sim 500$ kilotons of TNT was released during the explosion, which made it possible to estimate the mass of this space object as $\sim 10^{7} \mathrm{~kg}$.

Fragments of the Chelyabinsk meteorite which were defined as ordinary chondrite landed on the ground. This space object is a priori considered as a meteorite with an initial diameter of $\sim 19 \mathrm{~m}$. However, a number of inconsistencies were discovered in the process of studying this fall that makes it possible to doubt the meteorite nature of this space object. It was hypothesized $[1,2]$ that the Chelyabinsk meteorite was only a small part of the space object. The main body was a comet. Here we discuss some features of the destruction of this space object, which allow us to make a conclusion about the nature of this body. 


\section{THE BEGINNING OF THE OBJECT'S DESTRUCTION}

The object's trail started to form at an altitude of $70 \mathrm{~km}$. According to Borovička et al. [3], the width of the trail left by this space object along the entire length was about $2 \mathrm{~km}$. Therefore, particles flew away from the parent body at a distance of $\sim 1 \mathrm{~km}$. It is unlikely that this is due to the movement of evaporated meteorite molecules or molten droplets. According to eyewitnesses [4], the space object very quickly rotated during its flight, and substance was dumped by the jets in all directions.

It is considered that splitting of space bodies begins, when dynamic loads to the front surface of the body $P s$ exceed the strength of the substance of this body $\sigma_{c b}$.

$$
P_{s}=\frac{C_{D} \rho_{a} V^{2}}{2} \geq \sigma_{c b},
$$

where $C_{D} \sim 1$-the drag coefficient (for a sphere), $\rho_{a}$-the atmospheric density at this altitude and $V$-the speed of the object. From here we find the object's strength at the beginning of its destruction to have been $\sigma_{c b} \sim 6.5 \times 10^{3} \mathrm{~N} \cdot \mathrm{m}^{-2}$.

According to numerous observations, destruction of stone meteorites [5], to which meteorite Chelyabinsk relates, begins at dynamic loads of $3 \times 10^{5}-10^{6} \mathrm{~N} \cdot \mathrm{m}^{-2}$. The strength of the meteorite Chelyabinsk was $\sim 10^{6} \mathrm{~N} \cdot \mathrm{m}^{-2}$. This was determined by the scattering ellipse of meteorite substance which begins below the altitude of the trajectory $\sim 35 \mathrm{~km} \mathrm{[2],} \mathrm{where} \mathrm{the} \mathrm{dynamic} \mathrm{loads} \mathrm{on} \mathrm{the} \mathrm{meteorite} \mathrm{Chelyabinsk} \mathrm{were} \sim 1.3 \times$ $10^{6} \mathrm{~N} \cdot \mathrm{m}^{-2}$.

Thus, in the object which exploded over Chelyabinsk there could be two components with different strengths. Emission of substance as jets is characteristic of comets, hence, it is possible to assume that at an altitude of $70 \mathrm{~km}$ exactly a comet with low strength $\left(\sim 6.5 \times 10^{3} \mathrm{~N} \cdot \mathrm{m}^{-2}\right)$ began to be destroyed and its destruction ended in an explosion at an altitude of $30 \mathrm{~km}$. And a meteorite which had a strength $\sim 10^{6} \mathrm{~N} \cdot \mathrm{m}^{-2}$ began to be destroyed at an altitude of $\sim 35 \mathrm{~km}$.

\section{APPEARANCE OF THE TRAIL OF THE SPACE OBJECT}

The appearance and form of a trail left by the space object (Figure 1) was similar to trails of objects containing water, that is, a contrail from a jet plane and clouds. The trail of a jet plane consists of ice crystals which condensed on dust particles ejected from the plane. Clouds also consist of water droplets or ice crystals. The light orange color of the trail in the Chelyabinsk event is associated with oxides of nitrogen formed during ionization of the atmosphere. Moreover, it is important to note that this trail had a luminous edge (Figure 1). This luminosity is due to the refraction of sunlight by ice crystals, a characteristic of

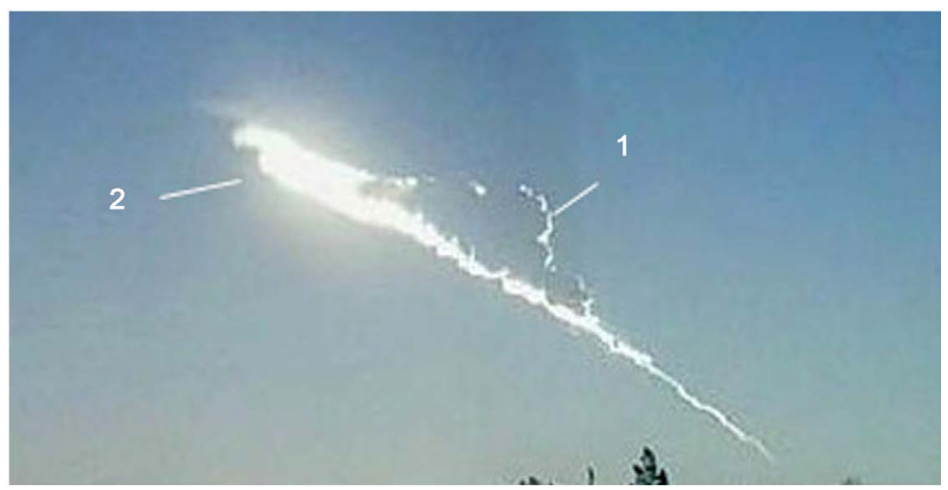

Figure 1. Photo by Sergei Vladelscikov, Kusa

(http://zhiznrajona.ru/uchyonye-gotovyat-knigu-o-mete orite-chelyabinsk-735/). 1-the luminous edge (the refraction of sunlight); 2 -the reflected sunlight. 
atmospheric clouds. We can also see that this trail reflects sunlight like ice crystals. Therefore, it can be assumed that the trail of the space object contained water in the form of ice crystals.

It should be noted that at altitudes of $30-70 \mathrm{~km}$ the atmospheric water is not enough to form a dense cloudy trail, which we observe in Figure 1. The Earth's atmosphere at an altitude of $50 \mathrm{~km}$ is so "dry" that clouds do not form there and, accordingly, are never observed. At an altitude of $30 \mathrm{~km}$, clouds are observed very rarely; they represent a thin transparent veil. A significant decrease in atmospheric humidity with altitude can be noted in Figure 2.

If the space object were a meteorite, its trail would be a dust cloud. Dust was thrown to an altitude of $50 \mathrm{~km}$ as a result of the explosion of the Krakatau volcano. It was noted that the dust blanket absorbs sunlight. In the Chelyabinsk event, the cloud reflects the light of the Sun, therefore, it can be assumed that water at an altitude of $30-70 \mathrm{~km}$ was brought by the space object itself. This means that part of this space object was a comet.

\section{SIMULATION OF CLOUD RISING OVER A BRIGHT RED SPOT}

Red (hot) spots (Figure 3) appeared at the place of slowed down dumped matter from the object. The origin of the glow in these spots is related to processes taking place in this substance. Clouds rising over the red spots are the result of the atmosphere's heating due to the energy released in these processes. We can suppose that the process which caused this heating was not only the liberation of the kinetic energy but also combustion. Combustion of the cosmic object's substance is possible only in case this object was a comet.

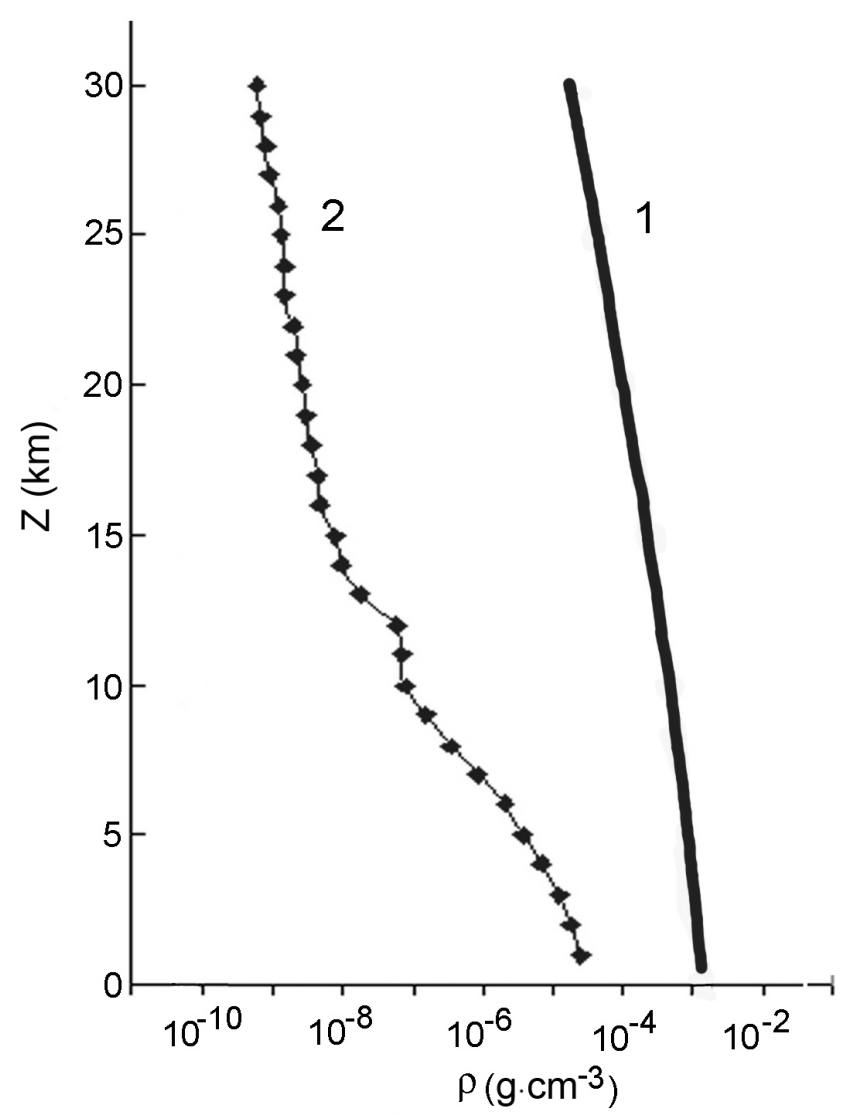

Figure 2. The standard atmosphere in the altitude range 0 - $30 \mathrm{~km}$ : 1-air density; 2-water content according to Lazarev [6]. 

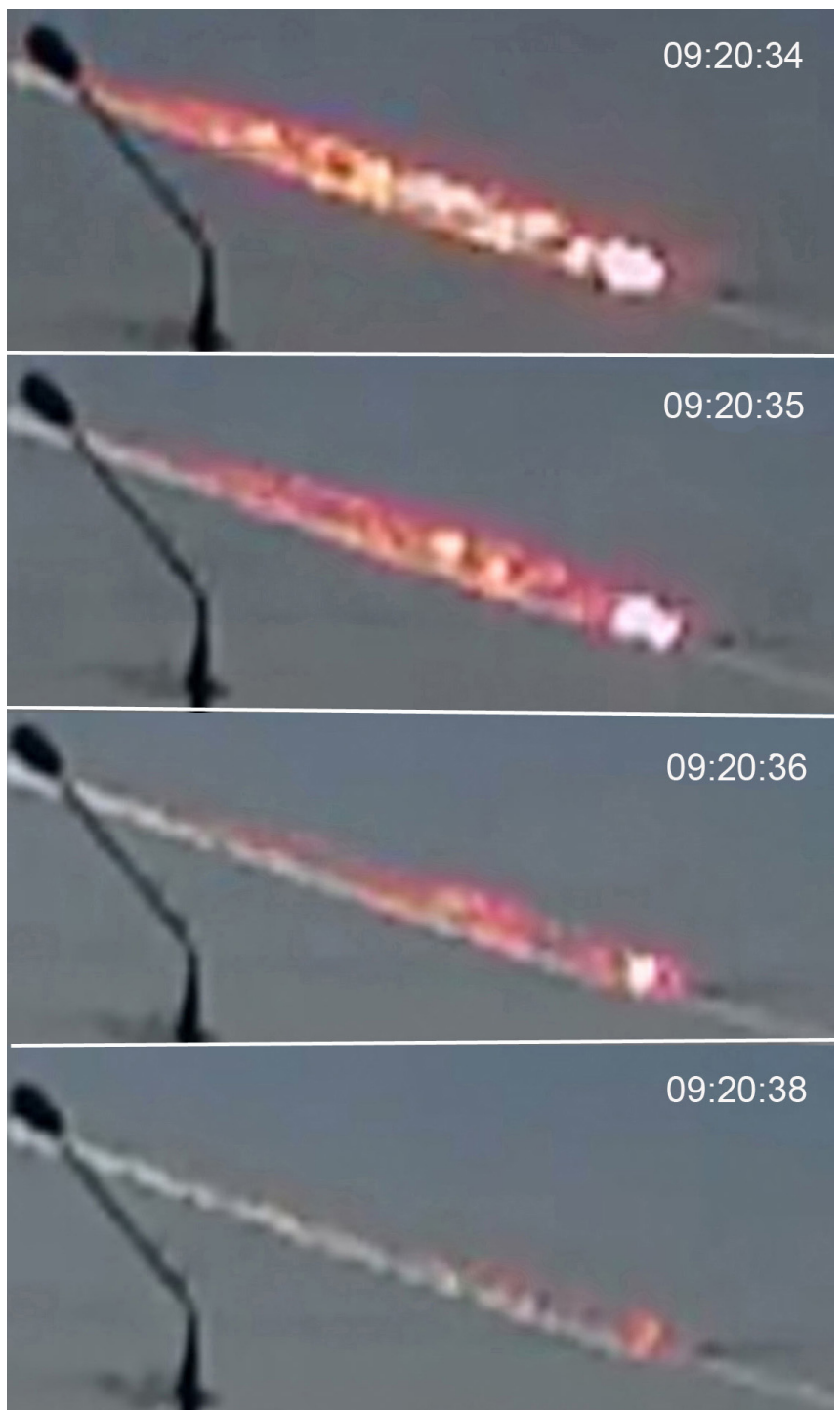

Figure 3. The red (hot) spots in the end of the object trajectory (video from Kamensk-Uralsky belongs to Alexander Ivanov and LPE360.com; https://www.youtube.com/watch?v=kFlpCT3v12E).

A model of the clouds rising should meet the following conditions. The core of a primary red spot in the first five seconds after the time of the object's flight rose by $\sim 450$ meters [3]. We assume that heated gas of a red spot represented a sphere-shaped cloud with an initial radius $r \sim 1000 \mathrm{~m}$ located at an altitude of $z=25.5 \mathrm{~km}$. The dependence of the atmosphere's temperature on altitude near Chelyabinsk for February 15, 2013 was taken from Miller et al. [7]. Atmospheric pressure at different altitudes was calculated using the barometric formula.

A rise of the cloud takes place under the action of forces [8-10]:

$$
F_{u p}=F_{A}-F_{G}-F_{R} \text {, }
$$

where $F_{u p}$ is the lifting force $F_{u p}=M \cdot W$, where $M=\rho_{g a s} \cdot V$ is the mass of rising gas with density $\rho_{g a s}$ (which depends on temperature $T$ ), $V$ is the cloud volume, and $W$ is acceleration of the lift; $F_{A}$ is the Archimedes force which is equal to $F_{A}=g \cdot V \cdot \rho_{a b}$ where $\rho_{a t}$ is the atmosphere density at the given altitude; $F_{G}=M \cdot g$ is 
the gravitational force acting on the cloud; $F_{R}$ is the resistance force

$$
F_{R}=\frac{C_{x} \rho_{a t} v^{2} S}{2},
$$

where $S$ is the cross-section area of the cloud and $V$ is the cloud lift speed, $C_{X}$ is the dimensionless coefficient of aerodynamic drag depending on the shape of a moving body. This coefficient determines which part of the ambient air starts moving together with the rising object. For a spherical shape of the object, this coefficient was experimentally determined as $C_{x}=0.24$. However, as was shown by observations of clouds in nuclear explosions, as well as rising balloons [8], deformations occur in the course of a rise and this coefficient can increase by a factor of $\sim 2$.

The calculations showed that a cloud can rise by $450 \mathrm{~m}$ in 5 seconds if its initial temperature is $T \sim 900$ $\mathrm{K}$. In other words, the temperature of the cloud of mass $M \sim 2.5 \times 10^{7} \mathrm{~kg}$ exceeds atmospheric temperature at this altitude by $\sim 700^{\circ}$.

\section{DISCUSSION AND CONCLUSION}

One more discrepancy with the meteorite nature of the space object concerns the fragments that reached the Earth's surface. Investigation of the meteorite fragments showed that some of them were directly irradiated by streams of solar cosmic rays [11]. Therefore, these fragments were located on the surface of this space object. The remaining fragments belonged to near surface layers of the space object. These fragments were located not deeper than $2.5 \mathrm{~m}$ from the surface [12] in spite of the fact that the radius of the Chelyabinsk meteorite was determined as $8.5 \mathrm{~m}$.

It is difficult to explain the complete evaporation of the inner part of the meteorite when the fragments from the surface layers survived. According to all theories of the destruction of meteorites, the outer layers of large bodies evaporate initially. All questions are removed, if we are dealing with a situation where a comet was united with the Chelyabinsk meteorite. At first the less strong comet disintegrates, and then meteorite fragments reach the Earth's surface.

So, we can suggest that in the Chelyabinsk event the space object was a comet merged with a meteorite.

\section{CONFLICTS OF INTEREST}

The authors declare no conflicts of interest regarding the publication of this paper.

\section{REFERENCES}

1. Nakamura, E., Kunihiro, T., Kitagawa, H., et al. (2015) Recycling of an Asteroid via a Comet Inferred from the Chelyabinsk Meteorite. 46th Lunar and Planetary Science Conference 2015, Contribution No. 1865.

2. Gladysheva, O.G. (2017) Did a Comet Deliver the Chelyabinsk Meteorite? European Planetary Science Congress 2017, 17-22 September 2017, Riga Latvia, id. EPSC2017-2.

3. Borovička, J., Spurný, P., Brown, P., Wiegert, P., Kalenda, P., Clark, D. and Shrbený, L. (2013) The Trajectory, Structure and Origin of the Chelyabinsk Asteroidal Impactor. Nature, 503, 235-237. https://doi.org/10.1038/nature12671

4. Gladyshev, S.G. (2013) Private Communication.

5. Levin, B.Yu. and Bronshten, V.A. (1986) The Tunguska Event and the Meteors with Terminal Flares. Meteoritics, 21.

6. Lazarev, A.I. (1979) Engineering Method for Calculating a Spectral Transparency of the Atmosphere in the Region $0.22-0.60 \mu \mathrm{m}$ for Sources of Non-Selective Radiation. L.: GOI. 105 p.

7. Miller, S.D., Straka III, W.C., Bachmeier, A.S., Schmit, T.J., Partain, P.T. and Noh, Y. (2013) Earth-Viewing Sa- 
tellite Perspectives on the Chelyabinsk Meteor Event. Proc Natl AcadSci US A, 110, 18092-18097.

8. Bogdanov, K. (2007) Up and Down through the Atmosphere. Kvant, No. 1, 9-13.

9. Pokrovsky, G.I. (1958) Physical Fundamentals of a Missile Flight. VORPNZ, Moscow, 42 p.

10. Revzin, S.V. (1951) Free Aeronautics. DOSAAF, Moscow, 124 p.

11. Galimov, E.M., et al. (2013) The Results of Analysis of the Meteorite Chelyabinsk. Geochemistry, No. 7, 580-598.

12. Povinec, P.P., Laubenstein, M., Jull, A.J.T., et al. (2015) Cosmogenic Radionuclides and Mineralogical Properties of the Chelyabinsk (LL5) Meteorite: What Do We Learn about the Meteoroid? Meteoritics and Planetary Science, 50, 273-286. 